\title{
AVALIAÇÃO DA APRENDIZAGEM: CONCEPÇÕES E OLHARES DE DOCENTES DO CURSO DE ODONTOLOGIA
}

\author{
EVALUACIÓN DEL APRENDIZAJE: CONCEPTOS Y FACULTAD DE \\ ODONTOLOGÍA MIRADAS DEL CURSO
}

\section{ASSESSMENT OF LEARNING: CONCEPTS AND PERSPECTIVES OF DENTISTRY COURSE TEACHERS}

\author{
Verydianna Frota CARNEIRO ${ }^{1}$ \\ Alice Maria Correia PEQUENO ${ }^{2}$ \\ Maria de Fátima Antero Sousa MACHADO ${ }^{3}$ \\ Dulce Maria de Lucena AGUIAR ${ }^{4}$ \\ Cleide CARNEIRO ${ }^{5}$ \\ Rithianne Frota CARNEIRO ${ }^{6}$
}

RESUMO: Avaliação da aprendizagem consiste em um mecanismo educacional contínuo que direciona a prática pedagógica, com base nos objetivos de aprendizagem propostos nos programas educacionais. $\mathrm{O}$ objetivo da pesquisa foi analisar $\mathrm{o}$ conhecimento de docentes de um curso de odontologia sobre avaliação da aprendizagem, em Fortaleza - CE. Trata-se de uma pesquisa com abordagem qualitativa, com coleta de dados realizada no período de setembro a outubro de 2014, por meio da análise documental e da técnica da entrevista semiestruturada. Adotou-se a modalidade Análise Temática, proposta por Minayo, para interpretação dos dados. Os resultados encontrados revelam que os docentes apresentam conhecimentos acerca da avaliação da aprendizagem, ao reconhecer a importância e as características dessa etapa no processo educativo.

PALAVRAS-CHAVE: Avaliação educacional. Docentes. Odontologia.

RESUMEN: Evaluación del aprendizaje consiste en un mecanismo de educación continua que dirige la práctica pedagógica basada en el aprendizaje de los objetivos propuestos en los programas educativos. El objetivo de la investigación fue analizar el conocimiento de los profesores de un curso de odontología en la evaluación del aprendizaje en Fortaleza-CE. Se trata de una investigación cualitativa, con la recogida de datos realizada en el periodo de septiembre a octubre de 2014, a través del análisis de documentos y la técnica de entrevista semiestructurada. Adoptado el método de

\footnotetext{
${ }^{1}$ Mestre em Ensino na Saúde pela Universidade Estadual do Ceará. E-mail: verydianna_1@ @otmail.com

2 Professora do Curso de Mestrado Ensino na Saúde da Universidade Estadual do Ceará. E-mail: alicepequeno@gmail.com

${ }^{3}$ Professora da Universidade Regional do Cariri, Ceará. E-mail: fatimaantero@uol.com.br

${ }^{4}$ Professora da Universidade de Fortaleza, Ceará. E-mail: dulcinha.aguiar@gmail.com

5 Coordenadora do Curso de Mestrado Ensino na Saúde em Fortaleza, Ceará. E-mail: cleide.carneiro@uece.br

${ }^{6}$ Docente do curso de Enfermagem da Faculdade Nordeste (FANOR) em Fortaleza, Ceará. E-mail: rithiannefrota01@ hotmail.com
} 
análisis temático propuesto por Minayo, para interpretar los datos. Los resultados mostraron que los maestros tengan conocimientos sobre la evaluación del aprendizaje, reconociendo la importancia y características de esta etapa en el proceso educativo.

PALAVRAS CLAVE: Evaluación educativa. Profesores. Odontología.

ABSTRACT: Learning evaluation consists of a continuous educational mechanism that directs the pedagogical practice, based on the learning objectives proposed in educational programs. The objective of the research was to analyze the knowledge of teachers of a dental course on assessment of learning, in Fortaleza. This is a research with qualitative approach with data collection conducted in the period from September to October 2014, through document analysis and semi-structured interview technique. It adopted the thematic analysis method proposed by Minayo to interpret the data. The results showed that teachers have knowledge about the assessment of learning, recognizing the importance and characteristics of this stage in the educational process.

KEYWORDS: Educational evaluation. Teachers. Dentistry.

\section{Introdução}

Avaliação da aprendizagem pode ser definida como um meio de obter informações sobre os avanços ou dificuldades dos alunos, constituindo um procedimento permanente de suporte ao processo ensino-aprendizagem e de orientação para o professor planejar suas ações, a fim de conseguir ajudar o aluno a prosseguir com êxito no seu processo de educação (FURLAN, 2007).

A avaliação no processo educativo, na concepção de Both (2007), se direciona à qualidade do desempenho sobre as atividades propostas, tanto para o aluno quanto para o professor. Na visão do autor, o foco principal é a qualidade do ensino, ultrapassando os limites da verificação.

Para Luckesi (2008), a avaliação da aprendizagem é uma forma de ajuizamento da qualidade do objeto avaliado, fator que implica uma tomada de posição a respeito do mesmo. Partindo desses pressupostos, a avaliação no presente estudo consiste em um mecanismo educacional contínuo que direciona a prática pedagógica, com base nos objetivos de aprendizagem propostos. Por meio dela, detectam-se progressos e obstáculos com a finalidade de melhoria do desempenho discente.

A Lei de Diretrizes e Bases da Educação Nacional (LDBEN) n 9.394, de 20 de dezembro de 1996, aponta a avaliação como um processo sistemático e cumulativo. A partir dessa lei os cursos existentes atualmente no país ganharam autonomia para elaborar o projeto político pedagógico (PPP), bem como o processo avaliativo, 
apresentando-se como uma construção coletiva para melhorar as práticas educativas (BRASIL, 1996).

Para Garcia (2009), a avaliação da aprendizagem na educação superior reflete não somente as escolhas pedagógicas exercidas pelos professores, mas também as diretrizes curriculares dos cursos universitários, ou, ainda, de modo mais amplo, a própria cultura institucional que os influencia.

No cenário mundial nos deparamos com um processo de transformação universitária, no qual as avaliações inseridas nos currículos da educação superior devem ser repensadas para compreender os reais impactos no desenvolvimento do aluno habilidades cognitivas, afetivas e psicomotoras, bem como a aquisição de competências clínicas - que na odontologia, estão relacionadas com o raciocínio clínico, o diagnóstico, a prescrição de cuidados e a terapêutica.

De acordo com as Diretrizes Curriculares Nacionais do Curso de Graduação em Odontologia (DCN/ODON) determinadas pela Resolução CNE/CES 3, de 19 de fevereiro de 2002, o processo formativo deverá utilizar metodologias e critérios para acompanhamento e avaliação da aprendizagem com o intuito de formar o cirurgiãodentista com perfil generalista, humanista, crítico e reflexivo, para atuar em todos os níveis de atenção à saúde, com base no rigor técnico e científico (CONSELHO NACIONAL DE EDUCAÇÃO SUPERIOR, 2002).

A publicação das Diretrizes Curriculares Nacionais (DCN) introduziu nos cursos de odontologia a necessidade de reconceituar o ensino integrado, pois o modelo de clínicas por especialidades estanques não mais contribui para o novo perfil do profissional (SANTOS et al., 2010). Diversos autores apontam que a formação do cirurgião-dentista deve estar voltada para a humanização, o trabalho multiprofissional e a vivência no Sistema Único de Saúde (SUS), mesmo diante da forte tendência à individualização e especialização (CAVALCANTI; CARTAXO; PADILHA, 2010; MORETTI-PIRES; BUENO, 2009).

Neste novo paradigma, o trabalho docente necessita também passar por uma profunda reflexão e transformação. Tradicionalmente, as práticas de avaliação da aprendizagem nas Instituições de Ensino Superior (IES) recaem sobre um conjunto limitado de escolhas que se concentram no uso de procedimentos exercidos ao final de um período ou unidade de ensino, onde tais estratégias evidenciam o uso da avaliação somativa. Diante dessa avaliação tradicional, torna-se necessária a inclusão de programas de desenvolvimento docente e discente em avaliação, na busca constante da 
coerência com os pressupostos pedagógicos estabelecidos pelo currículo (GARCIA, 2009).

Considerando que o objeto da pesquisa é a avaliação da aprendizagem no curso de graduação em odontologia, levantou-se as seguintes questões norteadoras: Qual o conhecimento dos docentes do curso de odontologia sobre avaliação do processo ensino-aprendizagem? Quais as características do processo avaliativo? Qual a compreensão sobre avaliação formativa e somativa?

Com o intuito de inspirar mudanças na avaliação discente do ensino superior, justifica-se a pesquisa, que pretende contribuir para repensar se os conhecimentos docentes sobre práticas avaliativas estão compatíveis com o desenvolvimento de profissionais críticos e reflexivos necessários para atuação no SUS.

O presente estudo objetivou analisar o conhecimento de docentes de um curso de odontologia sobre avaliação da aprendizagem.

\section{Abordagem metodológica}

O delineamento dessa investigação ancora-se no referencial da pesquisa social, com abordagem qualitativa de natureza descritiva, documental, em caráter transversal.

O estudo teve como cenário o curso de graduação em odontologia de uma instituição privada em Fortaleza - CE. A instituição foi selecionada por apresentar historicidade na formação de cirurgiões-dentistas, com o total de 1.474 alunos graduados no período de 1995 até 2014, e pelas mudanças apontadas nos últimos anos relacionadas ao processo formativo e a construção do currículo integrado.

Foram selecionados docentes que trabalham em regime de tempo de 40 horas e ministram aulas nas disciplinas obrigatórias dos três últimos anos do curso de odontologia, além de possuirem experiência de magistério igual ou maior a cinco anos no curso da instituição pesquisada.

A jornada de 40 horas foi aspecto considerado relevante pela maior dedicação do docente à ação pedagógica, com a plena oportunidade de planejamento das atividades, proximidade com a coordenação e instituição do curso e participação de reuniões destinadas ao alinhamento das ações.

Foram consideradas apenas as disciplinas obrigatórias dos três últimos anos da graduação, pelo predomínio de docentes exclusivos do curso de odontologia e pela 
introdução de disciplinas clínicas. Diante do modelo de currículo integrado proposto pela instituição, os primeiros anos da formação apresentam disciplinas comuns a todos os cursos do Centro de Ciências da Saúde (CCS).

Em relação ao tempo de ensino, cinco anos ou mais foi considerado aspecto inclusivo por representar o período mínimo para a conclusão do curso de bacharelado em odontologia. O tempo de experiência docente é importante para a incorporação dos valores institucionais. No total foram entrevistados 23 docentes que atenderam os critérios de inclusão descritos.

Os dados da pesquisa foram coletados no período de setembro a outubro de 2014, por meio da análise documental do Projeto Político Pedagógico e da técnica da entrevista semiestruturada, guiados por roteiros específicos.

A entrevista semiestruturada foi realizada pela própria pesquisadora e aconteceu no campus da instituição de ensino, de acordo com a disponibilidade dos docentes. A intenção da entrevista foi obter informações, reflexões e atitudes mais precisas e detalhadas sobre a avaliação da aprendizagem dos discentes do referido curso. A média da duração das entrevistas foi de 20 a 25 minutos.

Para garantir o sigilo adequado dos dados, as entrevistas foram gravadas com a permissão dos sujeitos e depois transcritas as falas na íntegra. Todas as gravações foram armazenadas em programas específicos do computador. A identificação dos sujeitos foi representada pela letra $\mathrm{P}$ e a numeração aleatória, para garantir o anonimato dos mesmos.

A análise dos dados ocorreu no período de outubro de 2014 a fevereiro de 2015. Os dados produzidos na pesquisa por meio das entrevistas semiestruturadas foram analisados pela técnica de Análise Temática proposta por Minayo, que consiste em descobrir os núcleos de sentido que compõe uma comunicação, cuja presença ou frequência signifiquem alguma coisa para o objeto analítico visado (MINAYO, 2013). Para a autora, a análise temática desdobra-se em três etapas: pré-análise, exploração do material e tratamento dos resultados obtidos, e interpretação.

$\mathrm{Na}$ análise documental do PPP do curso de odontologia foi realizado um recorte no que concerne à avaliação da aprendizagem, utilizando-se do roteiro com as principais etapas: Caracterização do documento; Codificação da unidade de análise; Registro em anotações, esquemas, diagramas ou outra forma de síntese; Análise crítica.

O estudo seguiu os princípios da bioética estabelecidos na Resolução 466/12, de 12 de dezembro de 2012, do Conselho Nacional de Saúde, que trata e regulamenta as 
diretrizes e normas envolvendo pesquisa com seres humanos, incorporando sob a ótica do indivíduo e das coletividades os referenciais básicos da bioética, tais como autonomia, não maleficência, beneficência, justiça e equidade, dentre outros, e visa a assegurar os direitos e os deveres que dizem respeito à comunidade científica, aos sujeitos da pesquisa e ao Estado (CONSELHO NACIONAL DE SAÚDE, 2012).

Antes da coleta dos dados, foi solicitada autorização formal à coordenação do curso, que participou do estudo, através da assinatura do Termo de Anuência. Pela utilização de um documento institucional, o Projeto Político Pedagógico do curso de Graduação em Odontologia, foi solicitado a assinatura formal do Termo do Fiel Depositário.

O projeto foi submetido ao CEP da Universidade Estadual do Ceará com sua aprovação em setembro de 2014, de acordo com o Parecer Consubstanciado de $\mathrm{N}^{\circ}$ 792.847. Os sujeitos do estudo foram convidados a participar em caráter voluntário, e ficaram cientes da importância da pesquisa, dos riscos, dos benefícios da pesquisa, da garantia do sigilo e anonimato das informações, bem como da possibilidade de desistirem em qualquer fase do estudo sem nenhum tipo de prejuízo, e seu consentimento ocorreu através da assinatura, em duas vias, do Termo de Consentimento Livre e Esclarecido (TCLE). Uma via ficou na posse da pesquisadora e a outra com o participante.

O estudo envolveu riscos de aspecto não físico, pois poderia causar constrangimento e/ou desconforto gerado pela entrevista, que foram minimizados pelo anonimato do pesquisado, bem como pela possibilidade de desistência do mesmo em qualquer fase da pesquisa. A participação dos sujeitos da pesquisa não acarretou nenhuma recompensa financeira, como também despesa financeira de nenhuma natureza.

\section{Resultados e discussão}

Os resultados do estudo serão apresentados a partir da definição de categorias temáticas, ilustradas com o recorte dos discursos dos entrevistados e confrontados com os componentes do Projeto Político Pedagógico do curso.

RIAEE - Revista Ibero-Americana de Estudos em Educação, v. 12, n. 2, p. 900-915, 2017 


\title{
Descobrindo os saberes docentes: a apropriação sobre a avaliação da aprendizagem
}

Essa categoria emergiu a partir do questionamento sobre conceito de avaliação da aprendizagem, suas características e a compreensão sobre avaliação formativa e somativa.

A avaliação da aprendizagem foi atribuída pela maioria dos entrevistados como simples ato de determinar ou mensurar o conteúdo repassado ao aluno no processo educativo, associando diretamente a instrumentos e/ou ferramentas de medida. Este conceito é muito estático, relacionado à aquisição de conteúdo e à educação tradicional e não proporciona melhorias no ensino. Associar a ideia de avaliar com a simples mensuração da aprendizagem segue de acordo com a racionalidade instrumental e reduz a intencionalidade da avaliação, voltando-se para a comprovação do rendimento dos educandos com base nos objetivos predefinidos.

\begin{abstract}
"[Avaliação da aprendizagem] é a gente buscar mecanismos que consiga saber do processo ensino- aprendizagem. O que esse aluno conseguiu receber das informações e conteúdos que foram trabalhados. Logo, é uma ferramenta que a gente utiliza para saber o que foi realmente a aprendizagem significativa dele dentro desse processo de ensino-aprendizagem [...]" (P2)
\end{abstract}

“[Avaliação da aprendizagem] é uma percepção do professor, uma forma de perceber se aquele aluno realmente entendeu aquele conteúdo [...]" (P4)

"Pra mim, a avaliação é você ter a percepção daquilo que foi ensinado. Se o aluno absorveu ou não aquilo que foi ensinado [...]" (P14)

"[Avaliar] é a maneira da gente mensurar o que está sendo passado e o que está sendo importante para o aluno naquele momento; o que está realmente ficando para o aluno naquele momento; o que está sendo significativo [...] Certamente nem tudo que é passado é considerado importante e fica [...] É uma maneira da gente mensurar até que ponto o que está sendo falado está sendo filtrado". (P17)

A avaliação não pode ser compreendida com uma atividade meramente técnica, relacionada somente a prova e exames, como expressaram alguns sujeitos. Os instrumentos são recursos utilizados no processo avaliativo e por meio deles chega-se aos resultados, obtendo o desempenho do discente. Associar o ato de avaliar somente a aplicação de instrumentos nos remete à visão antiga, da Pedagogia Tradicional ou Pedagogia dos Exames, termo utilizado por Ribeiro (2005) e Luckesi (2008), pautado 
na sociedade burguesa do século XVI e XVII, de um processo voltado para a realização de exames, e que pode ser evidenciado até os dias atuais.

Nas falas foram evidenciados também avanços quando os entrevistados apontam que é positivo e significativo ser avaliado, de acordo com os relatos:

"É importante para o aluno ser avaliado. Nesse momento, ele (aluno) sabe se está evoluindo ou se está estacionado, aonde precisa evoluir, onde estão as dificuldades" (P2)

"A avaliação é uma etapa muito significativa para os alunos, a partir disso, eles reconhecem seus pontos fortes e pontos fracos, responsabilizando-se pelo seu desenvolvimento [...]" (P16)

Os discursos apresentam termos como: "passar conhecimento" e "receber informações", que remetem a uma concepção de ensino fortemente enraizada e centrada no professor, na transmissão do conhecimento. O educador deve se libertar dessa compreensão e ser um sujeito crítico em sua prática docente, e forçar a capacidade crítica do educando, sua curiosidade, sua insubmissão, responsabilizando-o pelo próprio aprendizado. Paulo Freire (2011), no livro Pedagogia da Autonomia, enfatiza que ensinar não é transferir conteúdo e sim criar possibilidades ao aluno para sua própria construção.

Diante do exposto, infere-se que os docentes, com média de 21 anos de formação, trazem uma visão tradicional devido a seu modelo de formação e que as constantes mudanças institucionais que ocorreram no currículo e na formação docente possibilitaram avanços. O professor no papel de avaliador deve apresentar uma visão mais ampliada e incorporar no significado a finalidade do processo avaliativo.

O PPP do curso destaca o processo de avaliação da aprendizagem, com ênfase nas características, porém não foi detectado neste documento o conceito norteador. É necessário tornar explícito no documento que orienta a prática educativa o conceito sobre avaliação para, assim, direcionar o trabalho do educador.

Furlan (2007) relata que a avaliação não deve se restringir a uma noção simplista de medida. A educação tem o objetivo de socialização dos conhecimentos historicamente construídos, com finalidade do pleno desenvolvimento do educando e seu preparo para o exercício da cidadania e sua qualificação para o trabalho.

A avaliação deve ser entendida como um componente de diagnóstico e de reorientação do ensino e da aprendizagem pela compreensão da trajetória acadêmica do aluno (GRILLO; GESSINGER, 2010). Para Wiliam (2011), a avaliação é um ponto 
central na formação eficaz, e por meio dela podemos descobrir se uma determinada sequência de atividades instrucionais resultou em aprendizagem.

O projeto pedagógico, ao ser elaborado coletivamente, deve expor a missão da instituição, direcionando os critérios através dos quais as práticas educativas que estão sendo desenvolvidas serão avaliadas e que concepção os professores têm sobre o processo avaliativo (SILVA; ASSUMPÇÃO, 2012). Oliveira e Batista (2012) enfatizam a necessidade de a avaliação da aprendizagem do estudante estar coerente com os pressupostos epistemológicos que norteiam o currículo.

Poucos profissionais entrevistados destacaram a finalidade da avaliação. Para estes, o ato de avaliar oferece parâmetros para reorientar a ação pedagógica e melhorar o desempenho da aprendizagem dos estudantes. Fica explícita a avaliação com função diagnóstica para detecção das dificuldades dos estudantes.

Dessa forma, a avaliação deve ser compreendida como um meio e não um fim em si mesma para uma determinada pedagogia, envolvendo intencionalidade de ação, estando incorporado aa trabalho pedagógico docente, redirecionando o ensino, que deve ser compreendido como um processo contínuo, como referem os sujeitos:

“[...] a avaliação está relacionada com a aferição das dificuldades que o aluno apresenta para assim traçar maneiras de melhorar o aprendizado. Não é você somente emitir uma nota, ou dizer que está aprovado ou reprovado [...]" (P15)

"Às vezes, como professores, acreditamos que dominamos certo assunto e que trazemos para os alunos da melhor forma. Muitas vezes o aluno não tá motivado e descobrimos ao realizarmos a avaliação. A partir disso, podemos lançar mão de diversas metodologias para trazer de volta o interesse do aluno na disciplina, que parecia chata e cansativa [...]" (P19)

Para a superação da avaliação tradicional deve-se fazer uma reflexão sobre o conhecimento do docente, pois mesmo inserido em formação permanente, destaque observado no PPP do curso, foram evidenciadas lacunas sobre o processo avaliativo.

Para Luckesi (2008), a avaliação da aprendizagem é um mecanismo subsidiário do planejamento e da execução da prática pedagógica. Ela só faz sentido na medida em que serve de diagnóstico por meio dos resultados que estão sendo buscados e obtidos, sendo um instrumento auxiliar na melhoria da ação educativa.

Em relação ao momento em que deve ocorrer a avaliação da aprendizagem, os discursos evidenciam que a mesma deve ocorrer de maneira processual, ao longo do 
semestre, durante a disciplina, e principalmente, observando os alunos constantemente e não somente em um momento pontual. Nas atividades práticas este processo é facilitado porque cada professor se responsabiliza por grupos de dez discentes.

“[...] Pra mim é ao longo da execução do trabalho. Com o passar do tempo, conhecemos melhor os alunos, suas atitudes, suas posturas. [...] Ele fica sendo avaliado continuamente [...]" (P13)

"Na atividade prática nos responsabilizamos por uma quantidade menor de alunos, logo consigo me aproximar melhor deles e observálos melhor, realizando uma avaliação mais fidedigna, individualizada." (P16)

Neste aspecto, observou-se a coerência entre os componentes do PPP e as falas dos entrevistados, pois o documento destaca a avaliação de forma processual, com o acompanhamento pelo docente das atividades realizadas pelos estudantes. Para Fernandes e Pereira (2014) é imprescindível que os docentes estejam comprometidos com o projeto político pedagógico, pois tenderão a organizar suas atividades com base nas decisões tomadas coletivamente.

A possibilidade de avaliar longitudinalmente permite a observação do discente de forma progressiva durante a disciplina, com acompanhamento do seu ritmo participativo e produtivo, evidenciando sua evolução ou retrocesso. Entretanto, a realidade vivenciada pela maioria dos educadores não permite que ela seja realizada desta forma. O pouco tempo destinado para avaliar e o número elevado de alunos nas disciplinas são fatores limitantes do processual. Diante desta realidade, o professor não consegue executar um processo avaliativo formativo, privilegiando o domínio cognitivo com a verificação do conhecimento teórico, em detrimento dos demais domínios da aprendizagem, como mostram as falas:

"O aluno não pode ser avaliado somente durante a prova teórica. Existem vários momentos que eles são observados de uma forma crítica. A responsabilidade de avaliar um aluno somente em um determinado momento é muito grande. Às vezes, ele pode não estar bem para executar um procedimento. Quando eu o avalio processualmente posso realmente saber do que ele é capaz de executar com destreza, com habilidade [...]. Às vezes, nós não conseguimos utilizar um método mais ativo devido o grupo muito grande e nós não temos como diminuir. São muitos os alunos. Nesse caso temos que utilizar métodos que não sejam totalmente passivos, mas que consigamos trabalhar em grandes grupos [...]" (P2) 
"Avaliação é algo extremamente pessoal, cada aluno como uma pessoa diferente, cada um tem seu tempo de aprendizagem diferente. Deve-se entender o aluno, compreender ele diante de sua circunstância, das suas limitações e da evolução diante da limitação, analisando individualmente [...]" (P7)

Guerra (2007) ressalta que a avaliação não deve se converter num ato concreto que se realiza uma vez que a formação tenha terminado. Deve ser um processo que acompanha a aprendizagem. Furlan (2007) acrescenta que diariamente o docente deve identificar as várias situações que requerem avaliação de desempenho dos alunos.

Para Souza e Macedo (2012), a avaliação deve ser identificada como processo e não utilizada unicamente para detectar quantitativamente o que o discente memorizou. Ao ser realizada apenas em etapas estanques da formação dos alunos desconsidera o caráter processual da apropriação dos conceitos.

Os sujeitos relacionaram a avaliação formativa ao caráter processual durante a ação pedagógica, a promoção do diálogo e retorno das práticas avaliativas (feedback) e a intenção de subsidiar o trabalho do professor redirecionando ao ensino. Atualmente a avaliação formativa apresenta-se como uma forma ideal, pois ocorre durante o processo educativo, permitindo o feedback aos alunos e o replanejamento durante as ações educativas. Nos discursos abaixo, pode-se destacar que avaliação formativa permite um direcionamento não somente para o domínio cognitivo. As habilidades e principalmente as atitudes diante do paciente, da dupla e dos funcionários são competências analisadas na prática do curso de odontologia. É evidente a apropriação deste conceito pelos docentes, sendo fundamental para a mudança de atitude frente às ações pedagógicas, como referem as falas:

"O foco da avaliação formativa é observar o desempenho do aluno, seu progresso ou retrocesso. Às vezes o aluno inicia bem, com boas notas, mas depois ele pode ter uma queda, uma baixa no seu desempenho. Temos que analisar esse percurso do aluno. Não simplesmente que ele está com uma nota baixa, mas que ele estava com uma boa nota e teve uma queda [...]" (P12)

“[...] É essa avaliação diária que fazemos ao longo da formação deles. Todos os dias observamos sua postura diante do paciente, da dupla e dos funcionários. Isso são alguns quesitos que são importantes analisarmos." (P18). 
O PPP do curso descreve o processo avaliativo como periódico e sistemático, com a inclusão de procedimentos diversificados correspondendo à natureza da disciplina e às dimensões de caráter diagnóstico, processual e formativo.

Camargo e Mendes (2013) caracterizam a avaliação formativa como processual, colaborativa, flexível, pois ultrapassa os limites da sala de aula, contribuindo para que o educador se volte tanto para os processos individuais de seus alunos, como para o grupo e para a sua prática. Em outras palavras, os parceiros educativos e o professor se preocupam com a aprendizagem dos alunos, pelo modo como cada discente aprende e pelo modo como ele ensina. Enfatizam ainda que avaliação formativa pode ser considerada como uma modalidade fundamentada no diálogo, pois implica um processo permanente de reflexão, de ação contínua, processual e permanente, em que ensino e aprendizagem são redirecionados.

Para Villas Boas (2011), o caráter formativo da avaliação ajuda os alunos a localizar dificuldades e progredir na aprendizagem. A avaliação tem a finalidade de fornecer informações que permitem a reorganização do trabalho pedagógico em atendimento às diferenças individuais observadas. A avaliação contínua tem o potencial para apoiar a aprendizagem através do feedback do aluno e aumentar a motivação dos alunos para a aprendizagem (HERNÁNDEZ, 2012).

A maioria dos docentes relacionou o conceito de avaliação somativa com a média dos resultados obtidos pelo aluno, evidenciada no final do processo educativo. Eles recriminaram a avaliação somativa por apresentar caráter classificatório. Um número menor de educadores reconheceu a limitação por se apresentar no final de um período de aprendizagem, mas conseguiu evidenciar a necessidade e a importância para a instituição de ensino, que requer um registro em forma de nota, correspondendo a um balanço final e facilitando a visão do todo.

Os sujeitos pesquisados reconhecem o significado e os limites da avaliação somativa, no entanto, ela deve ser compreendida como uma etapa necessária na tomada de decisões e no julgamento da ação pedagógica. Por isso, não deve ser a única forma de avaliar os discentes, devendo estar presente no processo de aprendizagem, junto à avaliação diagnóstica e formativa.

“[...] Está relacionada com a soma dos resultados alcançados, por exemplo: o quanto o aluno tirou na média das notas durante o semestre. Com isso ele tem uma visão mais voltada para a nota, o valor da soma" (P5) 
“[...] Essa avaliação fornece a informação da soma das notas tiradas pelo aluno na disciplina. Acho que ela representa o resultado final, que às vezes nem sempre é justo com a evolução do aluno. Existem muitas variáveis que podem interferir nesse resultado final" (P8)

“[...] É o que as universidades utilizam para aprovarem ou reprovarem seus alunos. Como professor, eu não devo avaliar somente dessa forma. Está relacionada mais com aspectos quantitativos ao invés de qualitativos [...]" (P12)

“[...] Também através dessa avaliação, eles conseguem visualizar uma classificação devido à média. Não acho isso bom. Os alunos ficam se comparando quem é o melhor, quem é o pior. Não concordo com isso $[\ldots] "(\mathrm{P} 18)$

Depresbiteris (2009) esclarece que a avaliação somativa implica no fornecimento de informações a respeito do valor final do desempenho do educando, tendo em vista a decisão de aprová-lo ou reprová-lo.

Para Capello (2013), a avaliação somativa é aquela com que todos estão bastante familiarizados, pois se realiza em um momento específico e tem o objetivo de aferir se os objetivos traçados para o curso foram atingidos ao final do processo.

\section{Considerações finais}

Os resultados encontrados revelam que os docentes do curso de odontologia apresentam conhecimentos acerca da avaliação da aprendizagem, ao reconhecer a importância e as características dessa etapa no processo educativo. Nos discursos foi observado que a etapa avaliativa deve ser realizada de maneira longitudinal e as fases da avaliação (diagnóstica, formativa e somativa) devem se complementar para avaliar o aluno de forma integral. No entanto, os docentes ainda associam equivocadamente o ato de avaliar com a simples verificação de conhecimentos e o uso de instrumentos e ferramentas, e nos remetem a uma concepção de ensino fortemente enraizada na instrumentalização. A realidade de turmas com muitos alunos foi evidenciada como uma dificuldade para realizar adequadamente o processo avaliativo. O pouco tempo destinado para avaliar e o número elevado de alunos nas disciplinas são fatores limitantes do processo avaliativo. 


\section{Referências}

BRASIL. Lei n. 9.394, de 20 de dezembro de 1996. Estabelece as diretrizes e bases da Educação Nacional. Brasília, 1996. Disponível em: <http://portal.mec.gov.br/seed/arquivos/pdf/tvescola/leis/lein9394.pdf>. Acesso em: 14 de mar. 2017.

BOTH, I. J. Avaliação planejada, aprendizagem consentida: a filosofia do conhecimento. 1. ed., Curitiba: IBPEX, 2007.

CAMARGO, C. C. O.; MENDES, O. M. A avaliação formativa como uma política includente para a educação escolar. Revista Educação e Políticas em Debate, Uberlândia, v. 2, n. 2, p. 372-390, 2013. Disponível em: <http://www.seer.ufu.br/index.php/revistaeducaopoliticas/article/view/24825/13797>. Acesso em 14 de mar. 2017.

CAPELLO, C. Avaliação e o novo cenário da educação. Revista FGV Online, Rio de Janeiro, v. 3, n. 1, p. 4-10, 2013. Disponível em: < http://bibliotecadigital.fgv.br/ojs/index.php/revfgvonline/article/view/19289/18559>.

Acesso em 14 de mar. 2017.

CAVALCANTI, Y. W.; CARTAXO, R. O.; PADILHA, W. W. N. Educação odontológica e sistema de saúde brasileiro: práticas e percepções de estudantes de graduação. Arquivos em odontologia, Belo Horizonte, v. 46, n. 4, p. 224-231, 2010.

CONSELHO NACIONAL DE EDUCAÇÃO SUPERIOR. Institui Diretrizes Curriculares Nacionais do curso de graduação em Odontologia. Resolução CNE/CES 3/2002, de 4 de março de 2002. Disponível em: <http://portal.mec.gov.br/cne/arquivos/pdf/CES032002.pdf>. Acesso em 14 de mar. 2017.

CONSELHO NACIONAL DE SAÚDE. Aprova as diretrizes e normas regulamentadoras de pesquisas envolvendo seres humanos. Resolução $n^{\circ} 466$, de 12 de dezembro de 2012. Disponível em: <http://conselho.saude.gov.br/resolucoes/2012/Reso466.pdf>. Acesso em: 14 de mar. 2017.

DEPRESBITERIS, L. Avaliação educacional em três atos. 4. ed. São Paulo: Editora Senac. 2009.

FERNANDES, S. B.; PEREIRA, S. M. Projeto político-pedagógico: ação estratégica para a gestão democrática. Revista Ibero-Americana de Estudos em Educação, Araraquara, v. 9, n. 4, p. 985-1006, 2014. Disponível em: < http://piwik.seer.fclar.unesp.br/iberoamericana/article/view/6997/5327>. Acesso em: 14 de mar. 2017.

FREIRE, P. Pedagogia da autonomia: saberes necessários a prática educativa. 43. ed. São Paulo: Paz e Terra, 2011. 
FURLAN, M. I. C. Avaliação da aprendizagem escolar: convergências e divergências. São Paulo: Annablume, 2007.

GARCIA, J. Avaliação e aprendizagem na educação superior. Estudos em Avaliação Educacional, São Paulo, v. 20, n. 43, p. 201-13, 2009. Disponível em: <http://www.fcc.org.br/pesquisa/publicacoes/eae/arquivos/1489/1489.pdf>. Acesso em 14 de mar. 2017.

GRILlo, M. C.; GESSINGER, R. M. (Org.) Por que falar ainda em avaliação? Porto Alegre: EDIPUCRS, 2010.

GUERRA, M. A. S. Uma flecha no alvo: a avaliação como aprendizagem. São Paulo: Edições Loyola, 2007.

HERNÁNDEZ, R. Does continuous assessment in higher education support student learning? Higher Education, v. 64, n.4, p. 489-502, 2012. Disponível em: http://uncw.edu/assessment/documents/hernandez2012.pdf>. Acesso em 14 de mar. 2017.

LUCKESI, C. C. Avaliação da aprendizagem escolar. 19. ed. São Paulo: Cortez, 2008.

MINAYO, M. C. S. O desafio do conhecimento: pesquisa qualitativa em saúde. 13. ed. São Paulo: Hucitec, 2013.

MORETTI-PIRES, R. O.; BUENO, S. M. V. Freire e formação para o Sistema Único de Saúde: o enfermeiro, o médico e o odontólogo. Acta Paulista de Enfermagem, São Paulo, v. 22, n. 4, p. 439-44, 2009. Disponível em: <http://www.producao.usp.br/bitstream/handle/BDPI/3121/art_BUENO_Freire_e_form acao_para_o_Sistema_Unico_2009.pdf?sequence=1>. Acesso em 14 de mar. 2017.

OLIVEIRA, V. T. D.; BATISTA, N. A. Avaliação formativa em sessão tutorial: concepções e dificuldades. Revista Brasileira de Educação Médica, Rio de Janeiro, v. 36, n. 03, p. 374-80, 2012. Disponível em: <http://educa.fcc.org.br/scielo.php?script=sci_arttext\&pid=S1981-

$52712012000500012 \& \operatorname{lng}=$ es\&nrm=iso > . Acesso em 13 de mar. 2017.

RIBEIRO, A. I. M. Formação Do Gestor Educacional. Presidente Prudente: Arte \& Ciência, 2005.

SANTOS, L. P. et al. Estudo do perfil docente nos cursos de odontologia da região Sul. Revista de Iniciação Científica da ULBRA, Canoas, n. 8, p. 73-77, 2010. Disponível em: <http://www.periodicos.ulbra.br/index.php/ic/article/viewFile/365/288>. Acesso em 13 de mar. 2017.

SILVA, A. S.; ASSUMPÇÃO, E. Avaliação da aprendizagem. In: SUDBRACK, E. M., PIOVESAN, J. C. (orgs.) Trajetórias a serem construídas na docência: pesquisa PIBIC/EM no curso de Pedagogia [recurso eletrônico] - Frederico Westphalen: URIFrederico Westph, 2012. 88p. 
SOUZA, A. M. L.; MACEDO, M. C. S. R. Avaliação da aprendizagem e inclusão escolar: a singularidade a serviço da coletividade. Revista de Psicologia Escolar e Educacional, Maringá, v. 16, n. 2, p. 283-90, 2012. Disponível em: <http://www.scielo.br/scielo.php?script=sci_arttext\&pid=S1413-

85572012000200011\&lng=en\&nrm=iso>. Acesso em: 13 de mar. 2017.

VILLAS BOAS, B. M. F. (org.) Avaliação formativa: práticas inovadoras. Campinas: Papirus, 2011.

WILIAM, D. What is assessment for learning? Studies in Educational Evaluation, Londres, v. 37, n. 1, p. 3-14, 2011. Disponível em: <http://eprints.ioe.ac.uk/6806/1/Wiliam2011What2.pdf>. Acesso em 14 de mar. 2017.

\section{Como referenciar este artigo}

CARNEIRO, Verydianna Frota et al. Avaliação da aprendizagem: concepções e olhares de docentes do curso de odontologia. Revista Ibero-Americana de Estudos em Educação, Araraquara, v. 12, n. 2, p. 900-915, 2017. Disponível em: <http://dx.doi.org/10.21723/riaee.v12.n2.8486>. E-ISSN: 1982-5587.

Recebido em: 26/03/2016

Aprovação final em: 17/03/2017 